\title{
XIII. Description of a gas lamp for coal-mines, invented by Mr. E. Carter, of Exeter
}

\author{
Mr. E. Carter \& Sir H. Davy
}

To cite this article: Mr. E. Carter \& Sir H. Davy (1816) XIII. Description of a gas lamp for coalmines, invented by Mr. E. Carter, of Exeter, Philosophical Magazine Series 1, 47:213, 49-50, DOI: $10.1080 / 14786441608638795$

To link to this article: http://dx.doi.org/10.1080/14786441608638795

里 Published online: 27 Jul 2009.

Submit your article to this journal $[\pi$

Џ Article views: 4

Q View related articles $\square$ 


\section{[ 49 ]}

XIII. Description of a Gas Lamp for Coal-Mines, invented by $M r$. E. CARTER, of Exeter. Communicaled in a Letter from Mr. CARTER to Sir H. DavY*.

T Exeter, Dec. 27, 1815. SiR, - 1 HE many shocking accounts of accidents in coal-mines from the explosion of gas, induced me (no doubt with many others) to consider some means of preventing such dreadful accidents. The contrivance of a lantern that might be kept as it were insulated from the atmosphere of the mine, appeared the most likely mode of preventing explosion; and I thought mine, of which I have subjoined a sketch, would fully answer the purpose. When I was about sending this to the Editor of The Philosophical Magazine, your experiments and very learned observations on the subject, and very ingenious contrivance of a safetylantern, appeared in that work ; the excellence of which in simplicity and portability rendered it unnecessary, I thought, for mo to say any thing respecting mine. However, on reconsidering the matter, I am indiced to think that the coal-mines may be lighted with much advantage, in point of expense, with gas, as the material for its production rises on the spot. My first plan was intended for burning oil, and the addition of the pipe for conducting gas is the only alteration made.

The pipes $a$ and $b$ are main pipes, the one to conduct gas from the gasometer, the other to bring a supply of air to maintain

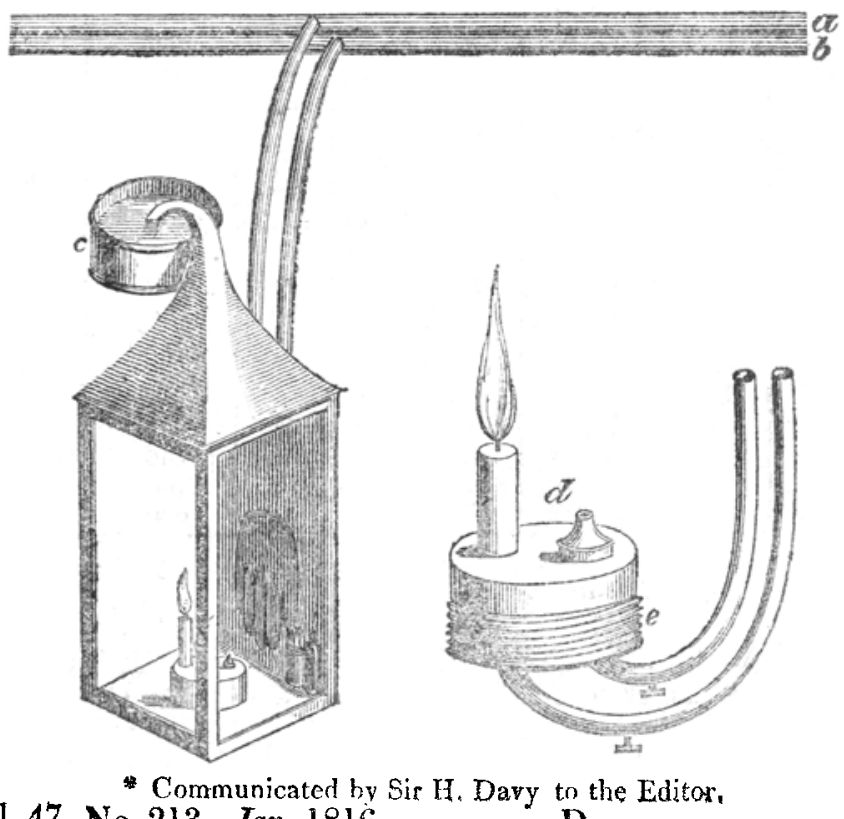

Vol. 47. No.213. Jan. 1816.

D

the 
the combustion: the air-pipe to be kept full by the degree of pressure that micy be found requisite from bellows kept in motion by the steam-engine; the size of the bellows to be proportioned to the number of lights that are to be fed. The lantern shoull be made perfectly air-tight, the crown of which should terminate, as represented in the sketch, by a tube immersed in water contained in the basin $c$. The air ritiated by combustion would run into the tube and be forced through the water by the pressure of air from the bellows. On one side of the lantern hangs an air-tiglit glove fastened round a hole sufficiently large to ahmit a man's haud; and on the same side ts a case of matches aud a bottle which may be ignited without air escaping from the lantern, or finding its way into the lantern from the mine. 'The aperture for the hand may be further secured by a door on the outside. $d$ is an enlarged sketch of the gas-burner and air-pipe which may be united with the lantern by the screw $e$.

Should this contrivance be founded on erroneous principles, which a very limited knowledge of seience makes me doubtful of, I hope that I siall be forgiven this intrusion, and that an atrempt to be uscful will, with Sir Humphry Dary, be suffecient: apology for any liberty of this nature.

$$
\begin{aligned}
& \text { I am, sir, } \\
& \text { Your most obedient humble servant, }
\end{aligned}
$$

E. CARTER.

To Sir H. Dain, Sof. Sorc. Bic.

*** The, idea of the "air-tight glove," suggested by Mr. Carter, deserves the attention of the mine-owners, as it furnishes a mean for relighting the lamp when extinguished, without any danger of an explosion. - Nole ly Sir H. Davy.

\section{Notices respecting New Books.}

On the Fire-tamp of Corl-mines, from the Phitosoplaical Transartions of the Royal Society. Irith an Advertisement containing an Account of an Invention for lighting the Mines and consuming the Fire-damp withont Danger to the Miner. By Sir Huaragy Davy, LL.D. F.R.S. T.R.I. Sro.

Sin H. Davy has published in an octavo form, the paper reark before the Royal Society, inserted in our last number. The publication is prefaced with the following advertisement, which deserves to be very generally made known, as it describes a dis- 